\title{
Progression of NMR studies of membrane-active peptides from lipid bilayers to live cells
}

\author{
M.-A. Sani \& F. Separovic*
}

School of Chemistry, Bio21 Institute, University of Melbourne, VIC 3010, Australia.

*fs@unimelb.edu.au

\section{Highlights}

- A perspective on solid-state NMR studies of membrane peptides is given.

- The structure and dynamics of both the peptide and lipid membranes can be studied.

- Heteronuclear distances between peptide and membrane atoms can be measured.

- Model membranes give structure-activity insights but in-cell studies are required.

\begin{abstract}
Understanding the structure of membrane-active peptides faces many challenges associated with the development of appropriate model membrane systems as the peptide structure depends strongly on the lipid environment. This perspective provides a brief overview of the approach taken to study antimicrobial and amyloid peptides in phospholipid bilayers using oriented bilayers and magical angle spinning techniques. In particular, Boltzmann statistics REDOR and maximum entropy analysis of spinning side bands are used to analyse systems with multiple states of peptide or lipid molecules may co-exist. We propose that in future, rather than model membranes, structural studies in whole cells are feasible.
\end{abstract}

\section{Key Words}

Solid-state NMR; antimicrobial peptides; amyloid peptides; phospholipid bilayers; oriented bilayers; MAS; REDOR; lipid-peptide interactions 


\section{Introduction}

As a tool of structural biology, NMR spectroscopy is employed primarily to determine the structure of proteins in the solution-state. However, solid-state NMR spectroscopy (ss-NMR) is being used increasingly to determine the structure of biomolecules despite limitations due to line broadening and sensitivity. Developments in ss-NMR have resulted in structural information being gained from membrane peptides, and even proteins, in complex lipid systems, that is difficult to obtain by other techniques. Starting from ${ }^{13} \mathrm{C}$ and ${ }^{15} \mathrm{~N}$ studies of the antibiotic peptide, gramicidin A, in phospholipid bilayers, ss-NMR structural studies have been extended to membrane receptors ${ }^{1}$. Progressively more complex model membranes are being used and we present some novel ss-NMR experiments (BS-REDOR, MeMAS) of these mixed lipid systems. Although structures in model membranes are seen as having biological relevance, the Holy Grail is to determine the structure at atomic resolution of these important biomolecules in their native environment. Solution NMR has been used to reveal the structure of over expressed proteins in living cells ${ }^{2}$, but the structure of membrane-active peptides in cells has not been reported. Using current ss-NMR technology and isotopic labelling, high-resolution structures of peptides in membranes of live cells are within reach.

\section{Preliminary concepts}

\section{Orientational dependence in NMR interactions}

In typical solution NMR experiments, biological molecules reorient with a correlation time well within the fast motion regime w.r.t. NMR time scale thereby averaging all angledependent interactions between the nuclear spins and the magnetic field, $\mathbf{B}_{\mathbf{0}}$, aligned with the $\mathrm{z}$-axis of the laboratory frame. With multidimensional approaches, NMR structures of soluble proteins have been resolved, up to $1000 \mathrm{kDa}$ with TROSY-based pulse sequences ${ }^{3,4}$. The presence of a lipid membrane environment for studying membrane proteins or membrane- 
active peptides, however, pushes the molecular motions into the slow regime. The interactions between a nuclear spin, I, and $\mathbf{B}_{\mathbf{0}}$ are no longer averaged and the chemical shift is described by an anisotropic second rank tensor, the trace of which gives the isotropic chemical shift, $\delta_{\text {iso }}$, given by $\delta_{\text {iso }}=\left(\delta_{\mathrm{xx}}+\delta_{\mathrm{yy}}+\delta_{\mathrm{zz}}\right) / 3$, whereas the elements of the chemical shift tensor are angular dependent, according to:

$$
\delta(\theta, \phi)=I_{l} \delta_{\text {iso }}\left[3 \cos ^{2} \theta-1-\eta \sin ^{2} \theta \cos (2 \phi)\right]
$$

where $I_{z}$ is the nuclear spin, $\theta$ and $\phi$ are the Euler angles used to describe the tensor in the laboratory frame, and $\eta$ is the asymmetry parameter described as $\eta=\left(\delta_{\mathrm{yy}}-\delta_{\mathrm{xx}}\right) / \delta_{\mathrm{zz}}$, which reflects the deviation from axial symmetry. The chemical shift anisotropy (CSA) is often described (using the Haeberlen convention) by $\Delta \delta=3\left(\delta_{\mathrm{zz}}-\delta_{\text {iso }}\right) / 2$, which describes the deviation from cubic symmetry. The CSA interactions dominate for nuclei of $\operatorname{spin} I=1 / 2$, such as ${ }^{31} \mathrm{P},{ }^{13} \mathrm{C}$ or ${ }^{15} \mathrm{~N}$.

Another important angular dependent interaction is the through space dipole-dipole interaction whereby each spin is influenced by neighbouring local fields as described by [Abragam, 1961]:

$$
D_{i, j}(\theta, \phi)=\frac{\mu_{0} \hbar \gamma_{i} \gamma_{j}}{8 \pi^{2} r^{3}}(A+B+\ldots+F)
$$

where $\mu_{0}$ is the vacuum permittivity, $\hbar$ is the reduced Planck constant, $\gamma_{\mathrm{i}, \mathrm{j}}$ is the gyromagnetic ratio of each individual spin, $r$ is the distance between the two nuclei,

$$
\begin{aligned}
& A=-I_{1 z} I_{2 z}\left(3 \cos ^{2} \theta-1\right) \text { describes the interaction between heteronuclear spins, and } \\
& B=\frac{1}{4}\left[I_{1+} I_{2-}+I_{1-} I_{2+}\right]\left(3 \cos ^{2} \theta-1\right) \text { is additional for homonuclear dipolar interactions. }
\end{aligned}
$$

Additional terms in Eqn $2(C-F)$ contribute to relaxation and are not required ${ }^{5}$. 


\section{Magic angle spinning}

In solid-state NMR experiments, high-resolution spectra can be achieved by using magic angle spinning (MAS) ${ }^{6,7}$. Angular dependent interactions with the magnetic field are mechanically averaged out by sample rotation $(0.2$ to $70 \mathrm{kHz})$, which modulates the spatial part of second rank tensors such as CSA [1] and dipolar coupling [2]. By tilting the sample at the so-called magic angle, $\theta=54.74^{\circ}$, and using spinning frequency, $v_{\mathrm{r}}$, larger than the dipolar couplings $D_{i, j}$, the spectrum is reduced to a single resonance at the isotropic chemical

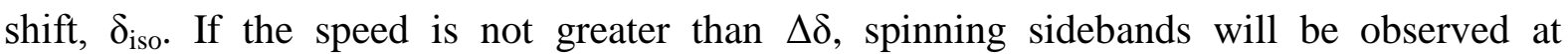
frequencies spaced at multiples of the spinning frequency $\left(\delta_{\text {iso }} \pm N v_{r}\right)$. The sideband intensities [3] can then be used for an accurate determination of the anisotropy and asymmetry of the CSA tensor (further discussed below).

$$
I\left(N, v_{r}\right)=\frac{1}{4 \pi^{2}} \int_{0}^{\pi} P_{2}(\theta) d \theta \int_{0}^{2 \pi} d \alpha \frac{1}{4 \pi^{2}}\left\{\left[\int_{0}^{2 \pi} d \gamma \cos \Phi\right]^{2}+\left[\int_{0}^{2 \pi} d \gamma \sin \Phi\right]^{2}\right\}
$$

where $P_{2}() \mu \sin ()$ for a spherical distribution of the nuclear tensor, and $\Phi^{\prime}$ gives the contribution to sideband, $\mathrm{N}$, at a spinning speed of $v_{\mathrm{r}}$ by a crystallite with chemical shift parameters $\delta$ and $\eta$, at an angle $(\alpha, \theta, \gamma)$ with respect to $\mathbf{B}_{0}{ }^{8}$.

However, homogeneous interactions, such are the homonuclear dipolar proton interactions, are not constant over time (flip-flop B term of [2]) and, therefore, are not fully averaged out under MAS conditions since the interactions must be constant for at least a rotor period. Interestingly, since the efficiency of the flip-flop decreases with $\mathbf{B}_{\mathbf{0}}$, experiments run at high field do not require as fast spinning speeds.

\section{Signal enhancement, signal filtering and decoupling schemes}

The field of solid-state NMR is blooming with techniques to enhance spectral resolutions and sensitivity. A major advance came with the cross-polarization (CP) technique ${ }^{9}$ where the 
magnetization from abundant spins, such as ${ }^{1} \mathrm{H}$, is transferred to dilute spins, such as ${ }^{13} \mathrm{C}$ or ${ }^{15} \mathrm{~N}$. At the matching spin locking Hartmann-Hahn condition, for example under MAS conditions $\mathrm{B}_{1}{ }^{\mathrm{H}}=\mathrm{B}_{1}{ }^{\mathrm{C}} \pm \mathrm{N} v_{\mathrm{r}}$, CP transfer is modulated by flip-flop transitions. This has two major benefits: it enhances the signal of the rare spins, for instance by a factor $\approx \gamma^{\mathrm{H}} / \gamma^{\mathrm{C}}=4$ for ${ }^{13} \mathrm{C}$ nuclei and depends on the longitudinal relaxation of protons $\mathrm{T}_{1}{ }^{\mathrm{H}}$, which is usually a magnitude faster than $\mathrm{T}_{1}{ }^{\mathrm{C}}$, thus allowing shorter recycle delays. Nowadays, many modern pulse sequences begin with a $\mathrm{CP}$ scheme. Another benefit that can be used results from the signal filtering that is produced under CP. As the CP transfer efficiency is modulated by dipolar interactions and, therefore, sensitive to the molecular motions of the observed spins, filtering of either slow or fast motions can be done by varying the spin locking time. This can be a valuable tool, for instance, when the ${ }^{31} \mathrm{P}$ signal of the more rigid lipid membrane is observed in live cells containing highly mobile phosphorous-containing molecules such as inorganic phosphate ${ }^{10}$.

Another way to enhance the signal and sensitivity of solid-state NMR experiments is to reduce the homogeneous spin-spin interactions, which can be averaged by radiofrequency (rf) pulses. This is called decoupling and is mainly aimed at suppressing the coupling between heteronuclear spins and protons. The first scheme used a high-power continuous wave (CW) and was replaced by the two-pulse phase modulation (TPPM) and the small phase incremental alternation (SPINAL) schemes, which are less compromised by interferences between heteronuclear couplings and the proton $\mathrm{CSA}^{11-13}$. These schemes, however, are less efficient at high spinning speed. Another pulse scheme that averages the homonuclear dipolar coupling is the Lee-Goldberg pulse train ${ }^{14,15}$ that takes advantage of an offset irradiation on the proton frequency that scales the proton chemical shift tensor by a factor $1 / \sqrt{ } 3$. 
Finally, by combining decoupling schemes and MAS conditions, one can achieve high resolution from otherwise crowded featureless solid-state NMR spectra, but at the cost of losing orientational information. This information, however, can be reintroduced by using rotor-synchronized rf pulses during the rotor period that recouple dipolar interactions. This has been successfully implemented to measure atomic distances between heteronuclear spins, a technique called REDOR or rotational-echo double-resonance ${ }^{16}$. Hence, the structure and location of, for instance, peptides in membranes can be obtained as REDOR provides a direct measure of short and long-range dipolar couplings and, therefore, the distance and the orientation of the internuclear vector with respect to the applied magnetic field can be determined. The ratio of signal obtained with a $\pi$ refocusing $\mathrm{rf}$ pulse $(\mathrm{S})$ and without $\left(\mathrm{S}_{0}\right)$ is a function of dipolar couplings whereby $S$ is dephased faster than $S_{0}$ which is simply experiencing transverse $T_{2}$ relaxation mechanisms. In the case of homonuclear spins, rotational resonance $(\mathrm{RR})$ can be used such as the case of melittin in phospholipid bilayers ${ }^{17}$.

\section{Gramicidin A in aligned lipid bilayers}

By aligning phospholipid bilayers between thin glass plates well resolved spectra can be obtained. Aligned multilayers can support up to $50 \% \mathrm{w} / \mathrm{w}$ water, which is sufficient to fully hydrate the phospholipids with about $2 \mathrm{~nm}$ of water between each bilayer ${ }^{18}$. These aligned systems result in two dimensional liquid crystals with respect to the magnetic field as the phospholipid long axis is oriented perpendicular to the glass surface. Using Eqn [1] the orientation of incorporated membrane proteins and peptides can be determined in macroscopically aligned bilayers placed in the magnetic field. Different conformations of aligned peptides result in different chemical shifts. Using specifically ${ }^{13} \mathrm{C}$ carbonyl labelled peptide, the conformation and orientation of the antibiotic ion channel, gramicidin A, was determined in aligned phospholipid bilayers ${ }^{18}$. The peptide was found to be a $\beta^{6.3}$ helix (Fig. 
1) and, in addition, the sodium ion was bound to Leu-10 in a right-handed transmembrane helix ${ }^{19,20}$. A high-resolution conformation of gramicidin A in an aligned lipid bilayer has been determined by ${ }^{15} \mathrm{~N}$ solid-state NMR ${ }^{21}$. The handedness of the helix was also confirmed by deuterium NMR of gramicidin A in oriented phospholipid bilayers ${ }^{22}$.

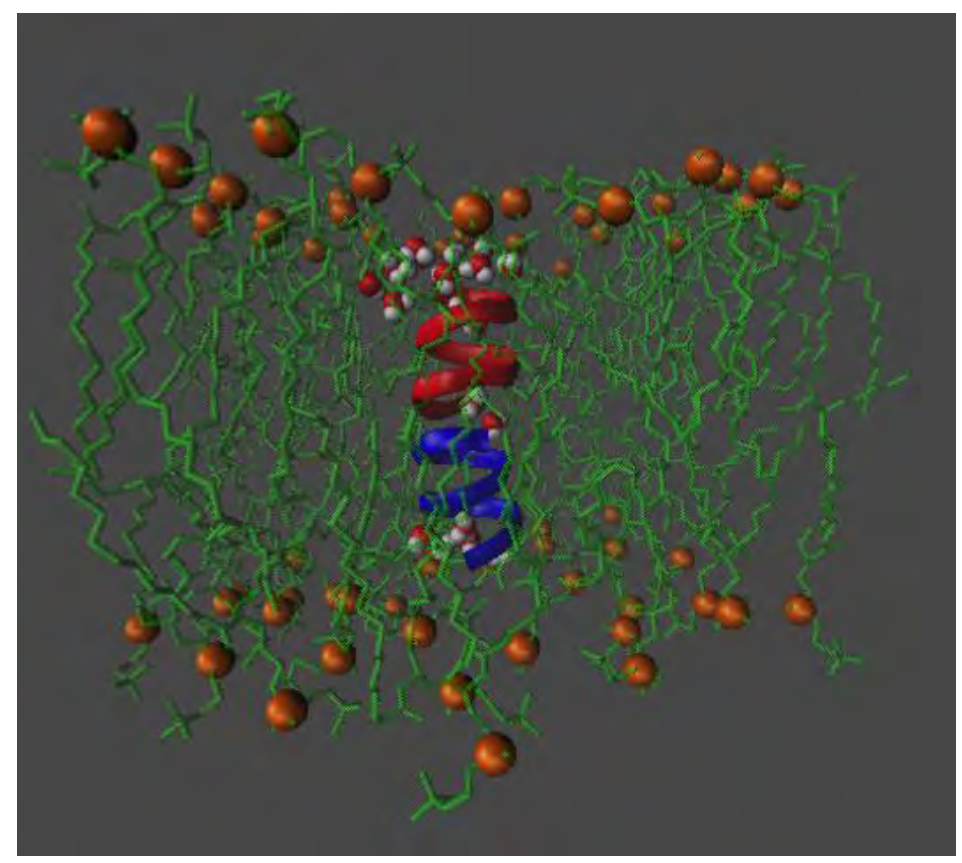

Figure 1 Model of gramicidin A dimer in DMPC bilayer obtained by MD simulations with the AMBER14 package. The PDB 1MAG was used as the starting configuration.

\section{Membrane-active peptides in model systems}

The structure and orientation of the lytic peptide, melittin, in aligned lipid bilayers was also determined using ${ }^{13} \mathrm{C}$ NMR ${ }^{23}$. Melittin formed a transmembrane $\alpha$-helix with a kink at Pro14. The structure of the peptide around Pro-14 was better defined using MAS techniques and double labels ${ }^{17}$. Interestingly, the peptide structure depended on the state of lipid bilayer above and below the lipid gel-fluid phase transition temperature. Similarly, antimicrobial peptides from Australian tree frogs ${ }^{24,25}$ show different orientations depending on the model membrane systems. The lipid composition of the membrane regulates the conformation and insertion of the antimicrobial peptide maculatin $1.1^{26}$ and the peptide activity ${ }^{27}$, which show 
the need for appropriate model systems. Recently, melittin peptides were shown to exhibit different activity on different cells and model membranes ${ }^{28}$. Increasingly we see the need for structural studies to be done in situ.

The amyloid- $\beta$ peptide (A $\beta 42)$ from Alzheimer's disease also is membrane-active. Solidstate NMR shows that the peptide disrupts lipid membranes and the effect is enhanced by metal ions found in amyloid plaques ${ }^{29}$. Both the lipid and the metal affect the peptide structure ${ }^{30}$, which is different to that of the fibril ${ }^{31}$. Also the lipid matrix plays a role in A $\beta 42$ fibril kinetics and morphology ${ }^{32}$ and solid-state NMR shows that copper modulates the interactions with model membranes ${ }^{33}$. Increasingly the need for better models of the membrane environment for membrane proteins and peptides is seen. Cubic phases are being used for crystallography ${ }^{34}$ and such systems ${ }^{35}$ could possibly be used for solid-state NMR structural studies of membrane peptides and proteins. Cubic phases give relatively narrow lines due to fast diffusion of lipids around highly curved surfaces and could be used for MAS studies to enhance spectral resolution.

\section{BS-REDOR}

REDOR is a useful MAS technique for determination of heteronuclear distances and is used to gain details of peptide structures and lipid-peptide interactions. However, care is required in setting up the experiment and in analysing the data since the signal intensity is prone to artefacts and complex spin-spin interactions. Thus, improvements to the original REDOR pulse sequence have been made, including: compensating for imperfect pulse angles (especially in low-sensitivity samples where pulse length calibration is difficult) by using xy8-REDOR ${ }^{36}$ and EXORCYCLE phase cycling schemes ${ }^{37}$; acquiring $\mathrm{S}$ and $\mathrm{S}_{0}$ signals consecutively (xy8- $\mathrm{S}_{0} \mathrm{~S}$ scheme) to avoid probe heating artefacts ${ }^{38}$; selecting specific and 
weak dipolar couplings in uniformly labelled ${ }^{13} \mathrm{C},{ }^{15} \mathrm{~N}$ peptides by using frequency selective REDOR (FSR) ${ }^{39}$; and multiple distances analysis by fitting a model distribution to the data using a Boltzmann statistics approach (BS-REDOR) ${ }^{38}$.

An application of the BS-REDOR analysis is presented in Figure 2 for the distance measurement between ${ }^{31} \mathrm{P}$ and $\mathrm{g} 3-{ }^{13} \mathrm{C}$ of unlabelled POPC/cholesterol $(6: 4 \mathrm{~mol} / \mathrm{mol})$ multilamellar vesicles (MLV). Two populations were obtained: a narrow distribution centred at $2.8 \AA(\sim 30 \%)$ and a broader distribution centred at $3.8 \AA(\sim 70 \%)$, which is consistent with intramolecular P-O-C (at an angle of $139^{\circ}$ ) and intermolecular P--C distances, respectively. These measurements, performed at natural abundance, could be useful for mapping the segmental orientations of the lipid headgroup for the validation of lipid force field used in molecular dynamics simulations. One can also use this approach to assess how peptides and proteins modify the headgroup structure and orientation in combination with the MeMAS technique reported below. Clearly, using a labelled peptide or protein allows performing a REDOR distance measurement between the lipid headgroup and the specific labelled site, thereby indicating the location and penetration depth. However, for in-cell studies the natural abundance background would be significant, so initial studies could be carried out using peptides with ${ }^{19} \mathrm{~F}$ amino acid residues. 

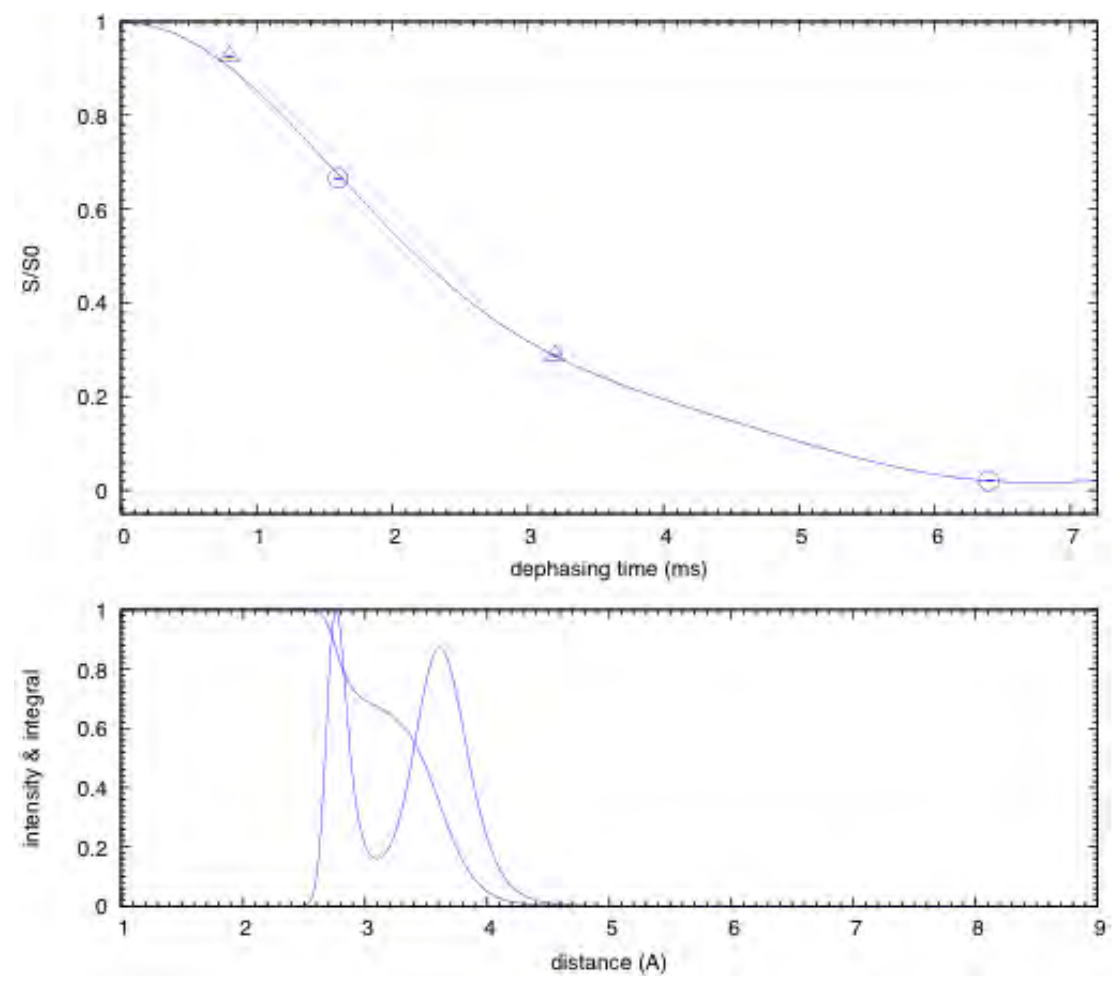

Figure 2 Upper: BS-REDOR reconstruction of ${ }^{13} \mathrm{C}\left\{{ }^{31} \mathrm{P}\right\}$ REDOR data of unlabelled POPC/cholesterol $(6: 4 \mathrm{~mol} / \mathrm{mol}) \mathrm{MLV}$ acquired with $\mathrm{xy} 8-\mathrm{S}_{0} \mathrm{~S}$ scheme at $10 \mathrm{kHz}$ spinning speed and $25^{\circ} \mathrm{C}$. The g3-carbon chemical shift was selected at $\sim 70 \mathrm{ppm}$ for this analysis. REDOR data points are plotted as triangles and circles to represent corresponding positive and negative Lagrange multipliers, respectively. Error bars are within the symbols. Lower: distance distribution obtained from the BS-REDOR analysis.

\section{Maximum entropy analysis of spinning side bands for accurate CSA determination}

Since lipid composition plays an important role in the regulation of membrane-active peptides and proteins, more complex lipid membranes are required which poses difficulty in retaining high resolution spectra. For instance, each lipid has its own chemical environment and thermotropism and thus a phospholipid mixture at a specific temperature displays a distribution in ${ }^{31} \mathrm{P} \delta_{\text {iso }}, \Delta \delta$ and $\eta$. To discern specific interactions between a peptide and a lipid in a mixture of lipids can become very tedious. Such interactions in binary and ternary mixtures can be resolved by averaging out the largest $\Delta \delta$ at sufficient MAS speed ${ }^{40-42}$, but 
with the caveats that the peptides disturb a detectable quantity of lipids and that sample heating due to high spinning speed is controlled. To overcome this necessity, we have applied low spinning MAS (temperature within $\pm 1^{\circ} \mathrm{C}$ ) with a maximum entropy analysis (MeMAS) on the side band intensities to extract CSA perturbations in a complex lipid sample and with a low peptide concentration ${ }^{8}$. MeMAS was carried out on a mixture of phospholipids at $37^{\circ} \mathrm{C}$ : dimyristoylphospatidylethanolamine and dimyristoylphospatidylglycerol, which have gel-tofluid phase transition temperatures of about $51^{\circ} \mathrm{C}$ and $24^{\circ} \mathrm{C}$, respectively. The membranes contain fluid and gel domains and, therefore, display entangled NMR signals. By using MeMAS, the CSA distribution was easily extracted by using three MAS speeds under $2 \mathrm{kHz}$ (about $1 \mathrm{hr}$ of acquisition each) and processed the data on a 12 CPU machine under $2 \mathrm{hr}$. Furthermore, MeMAS was performed with the addition of the antimicrobial peptide maculatin 1.1 at a lipid to peptide molar ratio of 50:1 (typically higher peptide concentrations are used for NMR studies), and a new CSA distribution was identified without difficulty ${ }^{8}$.

An example is presented in Figure 3, where the distribution of ${ }^{31} \mathrm{P}$ CSA and $\eta$ for a complex lipid mixture - brain total lipid extract - was obtained using the MeMAS method. In such an heterogeneous system, there is no hope of extracting the individual lipid CSA but instead the overall shift in distribution would be more valuable to monitor; for instance, when the amyloid-beta peptide seeds itself on the surface of this lipid membrane which mimics the composition of neurons. 


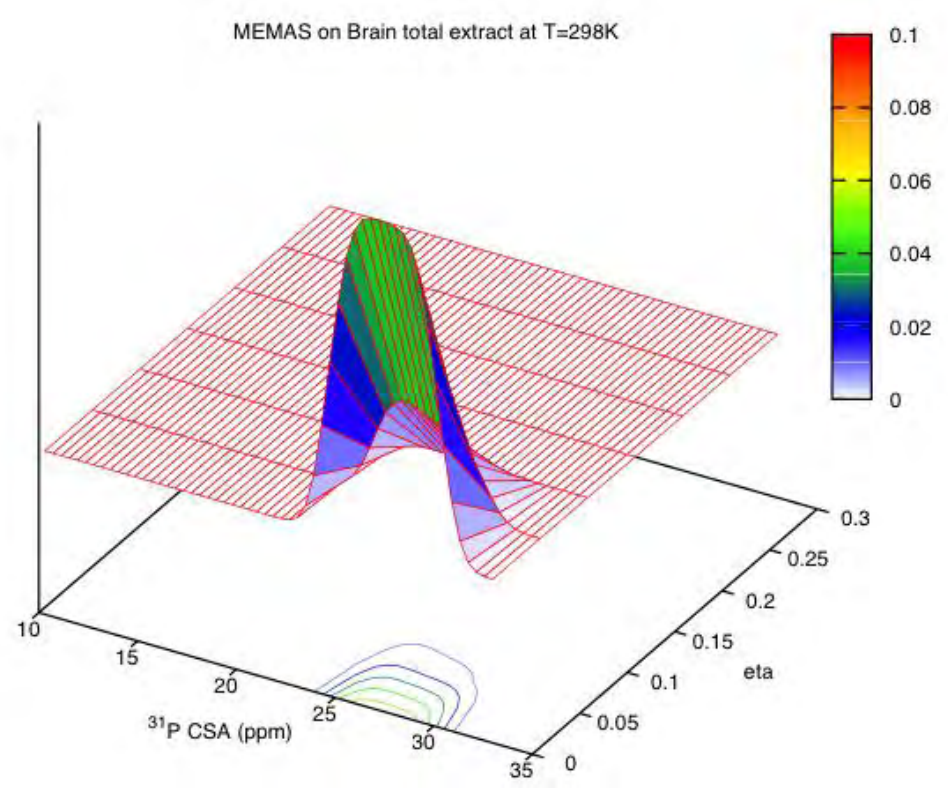

Figure 3 MeMAS analysis of ${ }^{31} \mathrm{P}$ spectra of brain total lipid extract obtained with MAS 700 $\mathrm{Hz}, 1000 \mathrm{~Hz}$ and $1700 \mathrm{~Hz}$ at $25^{\circ} \mathrm{C}$ on a $600 \mathrm{MHz}$ spectrometer. The z-axis represents the population for each CSA and $\eta$ value. The analysis was performed with CSA and $\eta$ resolutions of $0.4 \mathrm{ppm}$ and 0.05 , respectively.

\section{Towards live cell studies}

One of the biggest challenges in structural biology is how to deal with heterogeneous systems such as cell membranes. Ultimately, one would like to perform ss-NMR experiments in live cells under physiological conditions. However, several drawbacks need to be faced, such as:

1) natural membranes are extremely heterogeneous, which precludes control of specific interactions with lipid species or domains;

2) the limited lifetime of cells undergoing MAS conditions prevents long multidimensional experiments;

3) background signal is often significant and must be filtered; and

4) a multitude of conformational states may exist, giving rise to broad signals. 
${ }^{31} \mathrm{P}$ NMR spectra of E. coli ${ }^{43}$, sarcoplasmic reticulum ${ }^{44}$ and Acholeplasma Laidlawii ${ }^{45}$ membranes have been presented in early work. Despite poor signal to noise from these complex lipid mixtures obtained at low magnetic fields, they showed the heterogeneous composition of natural membranes. More recently, an NMR study of live mitochondria ${ }^{46}$ under apoptotic stress showed resolved spectral features and ${ }^{31} \mathrm{P}$ MAS distinguished the chemical environment perturbation for individual lipids. For studies of lipid membranes in live cells, ${ }^{31} \mathrm{P}$ CP MAS in combination with MeMAS analysis presents some advantages (Fig. 4). By using CP, the more mobile phospholipid molecules are filtered out by the short contact time and MeMAS analysis using moderate spinning speeds can reveal different lipid classes. For $E$. coli at $15^{\circ} \mathrm{C}$, two CSA were resolved (ca. $82 \mathrm{ppm}$ and $45 \mathrm{ppm}$ with an asymmetry $\eta$ of 1), indicating a 'gel' or immobile as well as a fluid lipid phase.
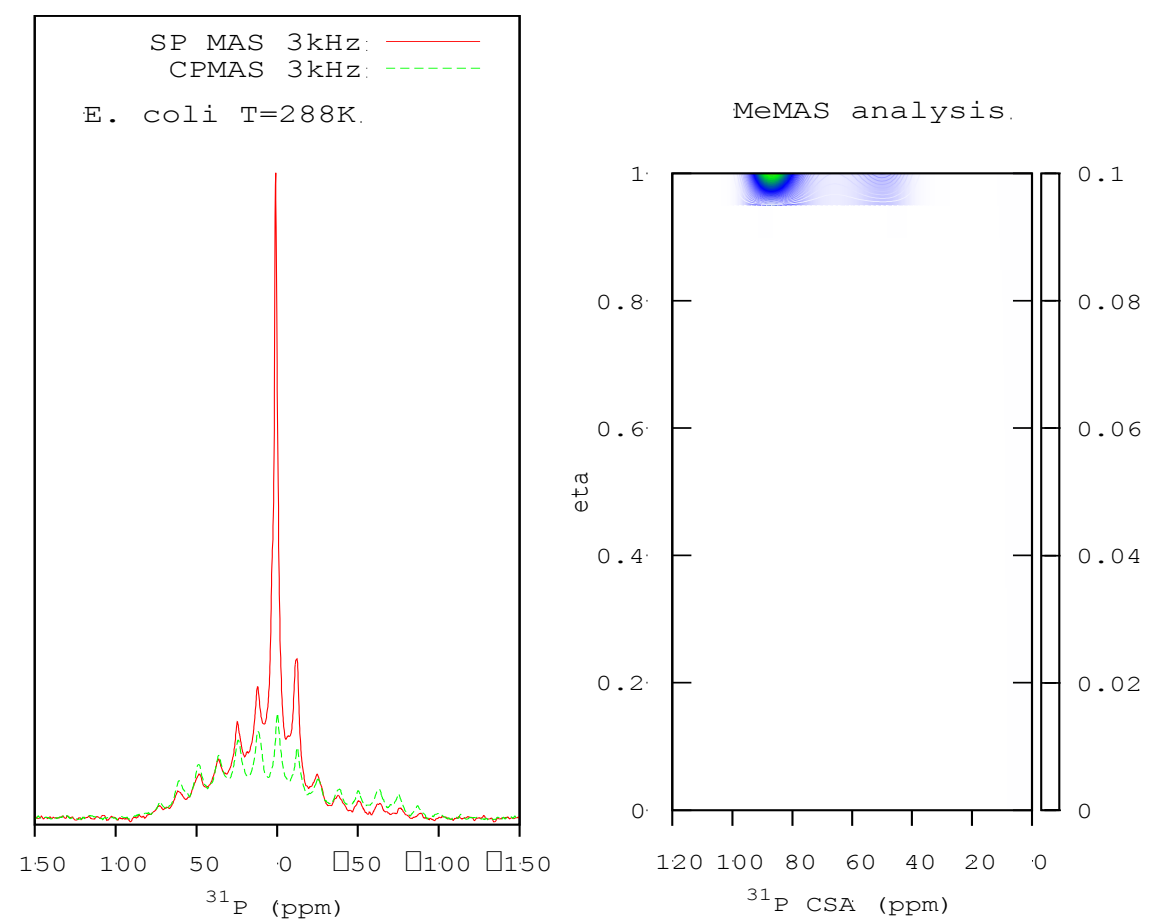

Figure 4 Left: ${ }^{31} \mathrm{P}$ CP MAS (red line) with $1 \mathrm{~ms}$ contact time versus single pulse (green line) of live E. coli in LB medium at $3 \mathrm{kHz}$ MAS and $15^{\circ} \mathrm{C}$. Right: MeMAS analysis of CP MAS ${ }^{31} \mathrm{P}$ experiments performed at $3 \mathrm{kHz}, 4 \mathrm{kHz}$ and $4.5 \mathrm{kHz}$. 
Nevertheless, solving the structure of membrane proteins in-situ remains a challenge, hence the numerous structural studies using dimyristoylphosphatidylcholine (DMPC) and DMPC / dimyristoylphosphatidylglycerol (DMPG), the latter used to mimic the negatively charged prokaryotic membranes ${ }^{47-50}$. Now it is possible to push the limits and perform ss-NMR on peptides and proteins in situ. Some recent achievements include characterisation of ${ }^{19} \mathrm{~F}$ labelled vancomycin binding sites in $S$. aureus bacteria using the REDOR technique ${ }^{51}$ and structural studies of oritavancin-peptidoglycan complexes in S. aureus by incorporation of ${ }^{13} \mathrm{C}$ and ${ }^{15} \mathrm{~N}$ amino acids into the bacterial glycan layer ${ }^{52}$. By specifically labelling the recombinant LR11 transmembrane domain with ${ }^{13} \mathrm{C}_{\alpha, \beta}$ alanine, the peptide structure was determined in native $E$. coli ${ }^{53}$. Finally, diacylglycerol kinase (DAGK), an E. coli membrane protein, was site-specifically ${ }^{19} \mathrm{~F}$ labelled and showed significant structural and dynamic differences in its native E. coli environment compared to detergent micelles ${ }^{54}$. This latter example illustrates the importance of studying membrane-active peptides and proteins in their natural environments. We propose to study specifically ${ }^{19} \mathrm{~F} /{ }^{13} \mathrm{C} /{ }^{15} \mathrm{~N}$ labelled antimicrobial peptides with live bacteria to determine structural changes in the peptides compared to model membrane systems. These studies could be extended to non-specifically ${ }^{13} \mathrm{C}-{ }^{15} \mathrm{~N}$ labelled peptides with bacterial cells. Developments in NMR methodology such as DNP ${ }^{55}$ and paramagnetic labels ${ }^{56}$, which greatly increase sensitivity, could also be applied to peptides and proteins in cells.

\section{Conclusion}

With the progress in pulse sequences, protein expression methods that enable specific in-situ labelling and a renewed appreciation of functionality of the lipid membrane, solving the structure-function relationship of membrane-active peptides or proteins and lipid composition 
is entering a new era. While great focus has been on solution NMR over the past three decades, ss-NMR now has the attention with the hope that it will reach similar success in determining the structure of biopolymers in their natural membrane environments.

\section{Acknowledgements}

FS is grateful to the Australian Research Council grant DP140102127 for financial support.

\section{References}

(1) Opella, S. J. Accounts Chem Res 2013, 46, 2145.

(2) Sakakibara, D.; Sasaki, A.; Ikeya, T.; Hamatsu, J.; Hanashima, T.; Mishima, M.; Yoshimasu, M.; Hayashi, N.; Mikawa, T.; Walchli, M.; Smith, B. O.; Shirakawa, M.; Guntert, P.; Ito, Y. Nature 2009, 458, 102.

(3) Fernandez, C.; Wider, G. Curr Opin Struc Biol 2003, 13, 570.

(4) Xu, Y. Q.; Matthews, S. Top Curr Chem 2013, 335, 97.

(5) Sani, M. A.; Separovic, F. In in Advances in Biological Solid-State NMR: Proteins and Membrane-Active Peptides; Separovic, F., Naito, A., Eds.; RSC Books: London, 2014, p 287.

(6) Andrew, E. R.; Bradbury, A.; Eades, R. G. Nature 1958, 182, 1659.

(7) Maricq, M. M.; Waugh, J. S. J Chem Phys 1979, 70, 3300.

(8) Sani, M. A.; Separovic, F.; Gehman, J. D. Biophys J 2011, 100, L40.

(9) Pines, A.; Gibby, M. G.; Waugh, J. S. J Chem Phys 1973, 59, 569.

(10) Chia, B. C. S.; Lam, Y. H.; Dyall-Smith, M.; Separovic, F.; Bowie, J. H. Lett Pept Sci 2000, 7, 151.

(11) Ernst, M.; Zimmermann, H.; Meier, B. H. Chem Phys Lett 2000, 317, 581.

(12) Gan, Z. H.; Ernst, R. R. Solid State Nucl Mag 1997, 8, 153.

(13) Levitt, M. H.; Bodenhausen, G.; Ernst, R. R. J Magn Reson 1983, 53, 443.

(14) Lee, M.; Goldburg, W. I. Phys Rev 1965, 140, 1261.

(15) Separovic, F.; Ashida, J.; Woolf, T.; Smith, R.; Terao, T. Chem Phys Lett $1999,303,493$.

(16) Gullion, T.; Schaefer, J. J Magn Reson 1989, 81, 196.

(17) Lam, Y. H.; Wassall, S. R.; Morton, C. J.; Smith, R.; Separovic, F. Biophys J 2001, 81, 2752.

(18) Cornell, B. A.; Separovic, F.; Baldassi, A. J.; Smith, R. Biophys J 1988, 53, 67.

(19) Separovic, F.; Gehrmann, J.; Milne, T.; Cornell, B. A.; Lin, S. Y.; Smith, R. Biophys J 1994, 67, 1495.

(20) Smith, R.; Thomas, D. E.; Atkins, A. R.; Separovic, F.; Cornell, B. A. Biochim Biophys Acta 1990, 1026, 161.

(21) Ketchem, R. R.; Hu, W.; Cross, T. A. Science 1993, 261, 1457.

(22) Prosser, R. S.; Daleman, S. I.; Davis, J. H. Biophys J 1994, 66, 1415.

(23) Smith, R.; Separovic, F.; Milne, T. J.; Whittaker, A.; Bennett, F. M.; Cornell, B. A.; Makriyannis, A. J Mol Biol 1994, 241, 456.

(24) Boland, M. P.; Separovic, F. Biochim Biophys Acta 2006, 1758, 1178. 
(25) Marcotte, I.; Wegener, K. L.; Lam, Y. H.; Chia, B. C. S.; de Planque, M. R. R.; Bowie, J. H.; Auger, M.; Separovic, F. Chem Phys Lipids 2003, 122, 107.

(26) Sani, M. A.; Whitwell, T. C.; Separovic, F. Biochim Biophys Acta 2012, 1818, 205.

(27) Sani, M. A.; Gagne, E.; Gehman, J. D.; Whitwell, T. C.; Separovic, F. Eur Biophys J 2014, 43, 445.

(28) Jamasbi, E.; Batinovic, S.; Sharples, R. A.; Sani, M. A.; Robins-Browne, R. M.; Wade, J. D.; Separovic, F.; Hossain, M. A. Amino Acids 2014 (in press).

(29) Lau, T. L.; Ambroggio, E. E.; Tew, D. J.; Cappai, R.; Masters, C. L.; Fidelio, G. D.; Barnham, K. J.; Separovic, F. J Mol Biol 2006, 356, 759.

(30) Gehman, J. D.; O'Brien, C. C.; Shabanpoor, F.; Wade, J. D.; Separovic, F. Eur Biophys J 2008, 37, 333.

(31) Balbach, J. J.; Petkova, A. T.; Oyler, N. A.; Antzutkin, O. N.; Gordon, D. J.; Meredith, S. C.; Tycko, R. Biophys J 2002, 83, 1205.

(32) Sani, M. A.; Gehman, J. D.; Separovic, F. Febs Lett 2011, 585, 749.

(33) Weber, D. K.; Gehman, J. D.; Separovic, F.; Sani, M. A. Aust J Chem 2012, 65, 472.

(34) Fraser, S. J.; Rose, R.; Hattarki, M. K.; Hartley, P. G.; Dolezal, O.; Dawson, R. M.; Separovic, F.; Polyzos, A. Soft Matter 2011, 7, 6125.

(35) Fraser, S.; Separovic, F.; Polyzos, A. Eur Biophys J 2009, 39, 83.

(36) Gullion, T.; Baker, D. B.; Conradi, M. S. J Magn Reson 1990, 89, 479.

(37) Sinha, N.; Schmidt-Rohr, K.; Hong, M. J Magn Reson 2004, 168, 358.

(38) Gehman, J. D.; Separovic, F.; Lu, K.; Mehta, A. K. J Phys Chem B 2007, 111,

7802.

(39) Jaroniec, C. P.; Tounge, B. A.; Herzfeld, J.; Griffin, R. G. J Am Chem Soc 2001, $123,3507$.

(40) Gehman, J. D.; Luc, F.; Hall, K.; Lee, T. H.; Boland, M. P.; Pukala, T. L.; Bowie, J. H.; Aguilar, M. I.; Separovic, F. Biochemistry 2008, 47, 8557.

(41) Pinheiro, T. J.; Watts, A. Biochemistry 1994, 33, 2459.

(42) Sani, M. A.; Dufourc, E. J.; Grobner, G. Biochim Biophys Acta 2009, 1788, 623.

(43) Horwitz, A. F.; Horsley, W. J.; Klein, M. P. P Natl Acad Sci USA 1972, 69, 590.

(44) Davis, D. G.; Inesi, G. Biochim Biophys Acta 1972, 282, 180.

(45) de Kruijff, B.; Cullis, P. R.; Radda, G. K.; Richards, R. E. Biochim Biophys Acta 1976, 419, 411.

(46) Sani, M. A.; Keech, 0.; Gardestrom, P.; Dufourc, E. J.; Grobner, G. FASEB J 2009, 23, 2872.

(47) Grage, S. L.; Wang, J.; Cross, T. A.; Ulrich, A. S. Biophys J 2002, 83, 3336.

(48) Yamaguchi, S.; Huster, D.; Waring, A.; Lehrer, R. I.; Kearney, W.; Tack, B. F.; Hong, M. Biophys J 2001, 81, 2203.

(49) Ramamoorthy, A.; Kandasamy, S. K.; Lee, D. K.; Kidambi, S.; Larson, R. G. Biochemistry 2007, 46, 965.

(50) Porcelli, F.; Buck, B.; Lee, D. K.; Hallock, K. J.; Ramamoorthy, A.; Veglia, G. J Biol Chem 2004, 279, 45815.

(51) Kim, S. J.; Cegelski, L.; Studelska, D. R.; O'Connor, R. D.; Mehta, A. K.; Schaefer, J. Biochemistry 2002, 41, 6967.

(52) Cegelski, L.; Steuber, D.; Mehta, A. K.; Kulp, D. W.; Axelsen, P. H.; Schaefer, J. J Mol Biol 2006, 357, 1253. 
(53) Fu, R. Q.; Wang, X. S.; Li, C. G.; Santiago-Miranda, A. N.; Pielak, G. J.; Tian, F. J Am Chem Soc 2011, 133, 12370.

(54) Shi, P.; Li, D.; Chen, H. W.; Xiong, Y.; Wang, Y. S.; Tian, C. L. Protein Sci 2012, $21,596$.

(55) Ni, Q. Z.; Daviso, E.; Can, T. V.; Markhasin, E.; Jawla, S. K.; Swager, T. M.; Temkin, R. J.; Herzfeld, J.; Griffin, R. G. Acc Chem Res 2013, 46, 1933.

(56) Otting, G. J Biomol NMR 2008, 42, 1. 


\section{University Library}

\section{- M M N E R VA A gateway to Melbourne's research publications}

Minerva Access is the Institutional Repository of The University of Melbourne

Author/s:

Sani, M-A;Separovic, F

Title:

Progression of NMR studies of membrane-active peptides from lipid bilayers to live cells

Date:

2015-04-01

Citation:

Sani, M. -A. \& Separovic, F. (2015). Progression of NMR studies of membrane-active peptides from lipid bilayers to live cells. JOURNAL OF MAGNETIC RESONANCE, 253, pp.138-142. https://doi.org/10.1016/j.jmr.2014.11.016.

Persistent Link:

http://hdl.handle.net/11343/52533 